\title{
GÉNERO
}

\section{Empoderamiento de mujeres en el Territorio Social La Conquista, Departamento Central, año 2018}

\author{
Jorge Morel Vera ${ }^{1}$, Raúl Alfredo Bernal ${ }^{1}$
}

\begin{abstract}
Resumen
Introducción: Esta investigación pretende determinar el empoderamiento de las mujeres de la comunidad, en base a datos sociodemográficos y así también visualizar la valiosa actuación de las mujeres como cabeza de familia y como miembro de una comunidad, que va progresando, teniéndola como líderes zonales. El Territorio Social La Conquista hoy día cuenta con 530 familias aproximadamente que fueron incorporándose dentro de estos 18 años de antigüedad que tiene la comunidad. Tiene un historial de invasión de 18 años y una superficie aproximada de 5 hectáreas, situado en la Comuna de Ñemby. El Territorio Social lleva el nombre en honor a la lucha por la permanencia en el lugar, haciendo frente a los desalojos existentes y logrando la conquista y obtención de la tierra propia. Lo resaltante de este asentamiento es la capacidad de organización y unidad de los pobladores, aun contando con diversidad en cuanto a la procedencia de éstos. Cabe destacar que la población que se instaló en el lugar como asentamiento; en los primeros tiempos, luego con la intervención de la SAS (hoy día Ministerio de Desarrollo Social); y el esfuerzo de los pobladores, se convierte hoy en día en un Territorio Social, denominación establecida por la Institución, que brinda su apoyo para el progreso de la comunidad.
\end{abstract}

Objetivo: Analizar el empoderamiento de las mujeres en el Territorio Social La Conquista del departamento Central.

Metodología:Setrabajóelempoderamiento desdelaautonomíasocioeconómica de las mujeres; en tal sentido se recolectó información acerca de la situación por la que atraviesan las mujeres del Territorio Social La Conquista dentro de su contexto familiar y su aspecto de liderazgo femenino. Para dicha investigación se utiliza el nivel descriptivo, con enfoque cuantitativo porque utiliza datos con medición numérica que proporciona las informaciones referentes al estudio. Se busca con esta investigación, determinar el conocimiento de las mujeres sobre el empoderamiento dentro del Territorio Social, sus derechos y obligaciones

\footnotetext{
1. Universidad Técnica de Comercialización y Desarrollo (UTCD). Facultad de Trabajo Social. Tesis presentada para acceder al Título de Lic. en Trabajo Social.

E-mail: jmvtrabajosocial@gmail.com

DOI: $10.26885 /$ rcei.foro.2018.96
} 
como así también consensuar definiciones básicas, incluyendo una definición sobre empoderamiento socioeconómico que contribuya a valorar el desarrollo saludable y el bienestar de las mujeres.

Resultados: Mujeres capacitadas para diseñar, elaborar y comercializar muebles - artesanía en pallet.

Conclusiones: El empoderamiento de las mujeres es un proceso deseable, y sin duda necesaria, que contribuye claramente al bienestar individual y familiar, a la salud y al desarrollo social; no es un proceso lineal, con un principio y un fin claramente definido y común para todos los individuos, sino que es un proceso que se experimenta de manera diferenciada y de alguna manera única por cada individuo, con lo que se define y desarrolla en función de la historia personal y del contexto de cada quien. Se puede mencionar que las mujeres en el Territorio Social La Conquista mínimamente se encuentran empoderadas, la mayor dificultad es el aspecto económico, pero con potencialidad para el desarrollo de habilidades para el liderazgo. Es necesario que las mujeres estén empoderadas socioeconómicamente con capacitación permanente y la comercialización dinámica de sus productos.

Palabras clave: empoderamiento, mujeres, territorio social.

\section{Referencias}

Ander-Egg, E. (1980). Metodología y práctica del desarrollo de la comunidad. Buenos Aires: El Ateneo.

Batliwala, S. El significado del empoderamiento de las mujeres: nuevos conceptos desde la acción. En M. León, M. (Ed.), Poder y empoderamiento de las mujeres. Santafé de Bogotá: TM Editores.

De León, M. (1997). Poder y empoderamiento de las mujeres. Coedición de Tercer Mundo Editores y Fondo de Documentación Mujer y Género de la Universidad Nacional de Colombia.

Rozas M., Fernández A. (1988). Políticas sociales y trabajo social. Buenos Aires: Editorial HV MANITAS.

Schuler, M. (1997). Los derechos de las mujeres son derechos humanos: la agenda internacional del empoderamiento. En Podery Empoderamiento de las Mujeres. 